\title{
The Competitiveness of Nations and Implications for Human Development
}

\begin{abstract}
Human development should be the ultimate objective of human activity, its aim being healthier, longer, and fuller lives. Thus, if the competitiveness of a nation is properly managed, enhanced human welfare should be the key expected consequence. The research described here explores the relationship between the competitiveness of a nation and its implications for human development. For this purpose, 45 countries were evaluated initially using data envelopment analysis. In this stage, global competitiveness indicators were taken as input variables with human development index indicators as output variables. Subsequently, an artificial neural network analysis was conducted to identify those factors having the greatest impact on efficiency scores.
\end{abstract}

\section{Keywords}

Competitiveness of nations, human development, data envelopment analysis, artificial neural networks 


\section{The Competitiveness of Nations and Implications for Human Development}

Füsun Ülengin ${ }^{a}$, Özgür Kabak ${ }^{b}$, Şule Önsel ${ }^{c}$, Emel Aktaş $^{b}$, Barnett R. Parker,

a (Corresponding Author) Professor, Dogus University, Faculty of Engineering, Department of Industrial Engineering, Acibadem, Kadikoy, 34722 Istanbul, Turkey, e-mail: fulengin@dogus.edu.tr, tel: +90 216 5445525, fax: +90 2165445535

${ }^{\mathrm{b}}$ Research Assistant, Istanbul Technical University, Faculty of Management, Department of Industrial Engineering, Macka, 34357 Istanbul, Turkey

${ }^{c}$ Assistant Professor, Dogus University, Faculty of Engineering, Department of Industrial Engineering, Acibadem, Kadikoy, 34722 Istanbul, Turkey

${ }^{\mathrm{d}}$ Professor, Department of Health Administration, Graduate School of Business, Pfeiffer University, Charlotte, NC 28209 USA, e-mail: Barnett.Parker@fsmail.pfeiffer.edu.

The month and year of Submission: October, 2008

Revised: July 2009; December 2009; July 2010; September 2010 


\section{Introduction}

The near future is expected to bring important changes to the world's economy and to the landscape of major industries. However, the ultimate goal of a nation should be to maximize some social welfare function incorporated with social conditions, environmental preservation, and income [5]. In this regard, a nation's competitiveness has been defined by Artto [6] as "the degree to which a nation can, under free and fair market conditions, produce goods and services that meet the test of international markets while simultaneously expanding the real incomes of its citizens."

The European Commission defines competitiveness as a measure of an economy's ability to create valuable goods and services so that both the population's standard of living and employment are raised [8]. The World Economic Forum aims to explain why some countries are more successful than others in raising income levels and opportunities for their populations [9]. Boltho [10] describes competitiveness as the longer-run aim of raising living standards, while Fagerberg [11] sees it more as the ability of a country to secure a higher standard of living than comparable countries for both the present and the future.

Costantini and Monni [16] state that human development has to be the first objective of international development policies, whereas an increase in human well-being is necessary to provide a sustainable path. A human development index (HDI) can be considered a first and important step toward incorporating broad concepts of sustainability into measures of development [17]. Mitschke [18] thus provides a classification for international competitiveness indicators on a time scale (short-term and long-term) with respect to economic scale (microeconomic and macroeconomic), where HDI is classified as a long-term macroeconomic indicator for standard of living.

The United Nations Development Program (UNDP) claims that social welfare is better evaluated using HDI rather than per capita GDP since the latter only reflects average income. A country such as Kuwait, with a very high per capita GDP thus has a lower HDI rank due, at least in part, to its poorer educational metrics. On the other hand, advanced Asian economies such as Japan, Korea, and Taiwan have all achieved exceptionally high rates of growth over the past 30-40 years. At the same time, there has been rapid human development in these economies, bringing them to levels similar to those of the advanced industrialized countries 
[12]. For example, Japan has the highest life expectancy (according to UN and WHO estimates) with very high living standards $\left(10^{\text {th }}\right.$ highest HDI $)$.

We recognize that a key challenge of development work is to ensure that benefits are shared as equitably as possible, and that the increasing interdependence of globalization works for people, and not just for corporate profits. Nevertheless, our research is based on the assumption that globalization of the world's economies may sometimes outpace the governance of markets with significant, and possibly negative, repercussions for the population.

If directed towards the needs of people, the competitiveness of a nation can bring advances for all humankind, but markets can sometimes undermine nonmarket activities considered vital for human development. Fiscal pressures can thus constrain the provision of social services; time can reduce the supply and quality of labor; and ill-conceived incentives may harm the environment. Globalization may also increase human insecurity as the spread of global crime, disease, and financial volatility outpaces actions designed to contain them [12, $13]$.

This paper follows the lead of the UNDP, which, in 2007, brought forth a study termed "Human Development Report" (HDR) which similarly focused on the materialistic aspects and physical well-being that more directly measure living conditions than human development per se. It does not, therefore, account for moral and spatial values. In particular, the importance of a "human development" concept in HDR is stated simply as: "The objective of development is to create an enabling environment for people to enjoy long, healthy and creative lives" [19].

The key objective of the current paper is to evaluate the validity of this proposition in so far as the competitiveness of a nation promotes better living conditions for its people. For this, we propose a methodology to objectively analyze the relationship between the competitiveness level of a country and its capability to enhance human development. As detailed below, we initially employ the well-known efficiency construct of data envelopment analysis (DEA). Artificial neural network (ANN) analysis is then utilized to identify those factors having the greatest impact on the resulting efficiency scores.

Section 2, of the paper describes the state of the art in measuring the performance of nations in terms of both their competitiveness and their human development. Section 3 summarizes 
the basic stages used in the proposed methodology, while in the fourth section; selected countries are evaluated on their DEA-based efficiency in converting competitiveness into human development outcomes. The relative importance of factors contributing to the efficiency scores are examined using ANN analysis in the fifth section. Finally, conclusions and suggestions for further research are given in Section 6.

\section{Measuring the Performance of Nations in terms of Human Development}

Very few studies have attempted a comprehensive comparison of the performance of nations [20]. In an earlier study by Golany and Thore [21], 72 countries were ranked by their economic and social performances. The inputs used included domestic investments and government expenditures on both economic and social programs. The performance of nations has been analyzed in the literature using a variety of metrics, including the global competitiveness index of Golany and Thore [22]. The schemes used in these efforts can be termed 'fixed-weight' in that they combine performance as a function of various attributes using pre-fixed weights, which may be chosen subjectively.

Boltho [10] espouses the view that long-term international competitiveness should result in citizens enjoying a relatively high economic welfare. In this regard, per capita income or gross domestic product can be viewed as more important than alternative indicators, possibly providing an early signal of a nation's international competitiveness. It is not clear, however, that purely economic indicators are sufficient for assessing/predicting either economic welfare or international competitiveness.

The composite indicator developed by the World Economic Forum [9], clusters countries based on their stage of competitiveness. Unfortunately, this classification tends to be rather subjective, or is based solely on per capita income.

The aim of this paper is to explore methodological transparency as a viable solution to problems created by existing aggregated indices. For this purpose, a methodology integrating data envelopment analysis (DEA) and artificial neural networks (ANN) is proposed to analyze the human development performance of countries with respect to their competitiveness. We are not offering a new index for human development, we rather compare nations in terms of their ability to transform their competitiveness power into human development. Because we believe that a nation's ultimate goal should be providing its citizens with higher standards of 
life in terms of health, education and economy so that the citizens are happier and welfare is at its highest level possible.

\subsection{Evaluation of Competitiveness: A Brief Review of the Literature}

Each year, selected organizations, such as the World Economic Forum (WEF) and the Institute for Management Development (IMD), apply several hundred objective and subjective indicators to assess the wealth created by the world's nations, and subsequently publish rankings of national competitiveness. These rankings serve as benchmarks for policy-makers and other interested parties into judging the competitive success of their country within a global context. Since 1989 the IMD jointly with the WEF has produced listings of national competitiveness in their annual World Competitiveness Yearbook (IMD) and Global Competitiveness Report (WEF) respectively [23].

The WEF uses three indices to analyze nations' competitiveness levels from both macroeconomic and microeconomic perspectives. Their Growth Competitiveness Index (GCI), developed by McArthur and Sachs [24], and Blanke and Lopez-Claros [25], is based on critical and, for the most part, macroeconomic environmental factors that influence sustained economic growth over the medium to long term. Porter's Business Competitiveness Index (BCI) [2], complementary to the GCI, investigates those company-specific factors that lead to improved efficiency and productivity from a microeconomic perspective. More recently, the Global Competitiveness Index [26] was designed to help unify the GCI and BCI, and may eventually replace them in the Global Competitiveness Report.

Note that the GCI is a highly comprehensive index for measuring national competitiveness. It thus captures both the microeconomic and macroeconomic foundations of national competitiveness.

The Global Competitiveness Index is based on three principles [26]: (1) The determinants of competitiveness are complex, competitiveness being composed of twelve pillars, each having a different weight for each stage of development. (2) Economic development is a dynamic process of successive improvement, i.e., it evolves in stages. In the most basic stage, called the factor-driven stage, firms compete on price and take advantage of cheap labor and/or unprocessed natural resources. In the second stage, called the efficiency-driven stage, efficient production becomes the main source of competitiveness. Finally, in the innovation-driven stage, successful economies can no longer compete on price or even quality and therefore 
must produce innovative products and practices using the most advanced methods of production and organization. (3) As economies develop, they move from one stage to the next in a smooth fashion.

While all twelve pillars apply to some extent in any given nation, the relative importance of each depends on a country's current stage of development. To take this into account, the pillars are organized into three subindices, each critical to one particular stage of development. The "basic requirements" subindex groups those pillars most critical for countries in the factor-driven stage, while the "efficiency enhancers" do the same for the efficiency-driven stage. The "innovation and sophistication factors" subindex includes all pillars critical to countries in the innovation-driven stage (See [22] for further details of the index.)

Fagerberg et al. [7] have developed indicators of key aspects of competitiveness and applied them in an analysis of selected nations' differing growth levels. They adopted a theoretical perspective that places emphasis on the role played by four dimensions of competitiveness; namely, technology, capacity, demand, and price/cost. The paper highlights the first three but, due to measurement problems, they are unfortunately not fully analyzed. Their aim was to more clearly understand why some countries consistently outperform others.

The concept of "national competitiveness" has been criticized in recent years. According to some research, defending national competitive interests is often a façade for asking for privileges for particular groups, or seeking to support economically harmful activities [12]. The WEF is clearly concerned with dynamic comparative advantage and emphasizes that the ability to sustain income and growth depends, in a globalized world, on each country's ability to innovate, or import and utilize technologies created elsewhere.

WEF's indices thus assign uniformly higher values to freer trade, stronger intellectual property protection, and more liberal capital accounts across nations. However, the WEF has not yet analyzed whether a highly competitive country is also one that uses such power for the sake of human development [12]. For example Aiginger [29] presents a framework for evaluating the competitive position of nations by relating competitiveness to the concept of welfare maximization. Thus, if the competitiveness of a country is properly managed, enhanced human welfare should be an expected consequence. In fact, healthier, longer and fuller lives of its populace $t$ should be the ultimate objective of a nation's activities [27]. 
In this regard, it is important to note that there is a bi-directional link between human development and economic growth. The latter can thus be seen as the major instrument for advancing the former. Achievements in human development can, in turn, make critical contributions to economic growth. In fact, since human development should be the ultimate goal of human activity [25, 28] welfare maximization should naturally seek optimal utilization of those resources needed to satisfy the economics ends of a society [29].

\subsection{Evaluation of Human Development: A Brief Review of the Literature}

The original definition of human development was given in the UNDP Human Development Report (HDR) as follows [19]:

\footnotetext{
"Human development is a process of enlarging people's choices. In principle, these choices can be infinite and change over time. But at all levels of development, the three essential ones are for people to lead a long and healthy life, to acquire knowledge and to have access to resources needed for a decent standard of living. If these essential choices are not available, many other opportunities remain inaccessible."
}

The UNDP claims that the Human Development Index (HDI) is superior to per-capita GDP for measuring social well-being as the latter measures only income, whereas the HDI is also weighted for longevity and education. Moreover, per-capita GDP only reflects average income, whereas the HDI is influenced by the type of goods that constitute GDP.

The HDI is a function of three basic dimensions of human development: (1) A long and healthy life, as measured by life expectancy at birth; (2) knowledge, as measured by the adult literacy rate (with weight $0.67 / 1.00$ ) 1) and a combined primary, secondary, and tertiary gross enrollment ratio (with weight 0.33/1.00); and (3) a decent standard of living, as measured by per-capita GDP. Before the HDI is itself calculated, an index must be created for each of its three dimensions. The details of such calculations are given in UNDP [31].

\subsection{Drawbacks of the Current Indices}

The various indices, discussed above, that have been designed to measure the competitiveness and human development levels of nations have been subject to criticism, some rather severe, in the literature. One major concern is related to the subjectivity of the criteria weights. For example, Onsel et al. [33] raised this question for the WEF indices, suggesting that their uniform application to every country may incorrectly penalize some while benefiting others. . In order to aggregate the various hard and soft data into a unified 
composite indicator, the WEF uses a fixed set of weights that are then applied uniformly to the underlying data for each country under analysis.

Another important drawback identified in the literature is the additivity assumption (that the parameters are added to reach a global score), which is not always valid under real-world conditions [32]. The result of such an additivity assumption can be a bias in the ranking of nations. Basically, the compensatory nature of the assumption allows for countries performing well on one criterion but poorly on another to be assessed the same rank with another country that is an average performer across all criteria. Oral and Chabchoub [32, 33], using detailed mathematical modeling, showed that the methodology underlying the World Competitiveness Yearbook is difficult to understand, and thus suggested a need for alternative/improved statistical or mathematical programming techniques.

Although many view competitiveness synonymously with productivity, these two interrelated terms are, as noted earlier, quite different. Oral et al. [36] differentiate the two in noting that (organizationally) productivity refers to the internal capability of an organization, while competitiveness refers to the relative position of an organization vis-à-vis its competitors. However, national competitiveness is defined as that set of factors, policies, and institutions that determine the level of productivity of a country; thus, competitiveness is measured by productivity that supports high wages, a strong currency, and attractive returns to capitaland, with them, a high standard of living [9].

Since its establishment, the HDI has met with considerable criticism of its various attributes, such as the way its component indices are derived from the raw data, and the additive nature of the aggregation method. Another critical issue of the HDI is the fact that equal weights are given to its component indices. Although this assumption has been supported in the UNDP's HDRs, it has nevertheless been met with considerable criticism in the literature [37-38].

Detailing the full set of drawbacks of the various indices used to measure competitiveness and/or human development is beyond the scope of the current research. However, they are necessary to note, since, by our employing d data envelopment analysis (DEA), we directly address the key concerns of existing indices' use of predetermined subjective weights and additivity assumptions. 


\subsection{Relationship between Competitiveness and Human Development}

To the best of our knowledge, the relationship between competitiveness and human development has not been analyzed in depth in the literature. Ranis et al. [27] investigated the connection between economic growth and human development, indicating a strong connection is likely. On the one hand, economic growth provides the resources for improvements, possibly sustained, in human development. Conversely, improvement in the quality of the labor force is an important contributor to economic growth. However, the authors acknowledged that, while this two-way relationship may now be widely accepted, the specific factors linking the two elements have not been systematically explored.

Davies and Quinlivan [5] performed panel analyses on the impact of trade on human development. They found that the standard argument for a positive relationship between the two is that more trade generally results in a higher standard of living, which, in turn, generates improved education, health care, and social services. The standard argument rests on the premise that the influence of trade on income is direct, while the influence of trade on nonincome measures is indirect, being transmitted via income [5]. Trade results not merely in an increase in the quantity of goods consumed, but in an increase in the variety of such goods.

In the case of a developing nation, new types of goods generally include medicines, healthrelated equipment, and medical training - all of which improve the health, nutrition, and longevity of a nation's populace. Improvements in trade will likely result in some immediate economic gains which will, in turn, stimulate future increases in literacy and health as peoples' standards of living rise and the opportunities for returning to school expand. Importantly, Davies and Quinlivan [5] further found that increases in trade are positively associated with future increases in a nation's social welfare.

\section{Framework of the Proposed Methodology}

Our proposed methodology, comprising two stages, aims to determine how efficient countries are using their competitiveness for improving human development. In the first stage, a DEA is conducted to measure the efficiency with which countries use their competitiveness to benefit their citizens. For this purpose, scores on the three principal dimensions of the WEF's global competitiveness index, namely, basic requirements (BASREQ), efficiency enhancers (EFFENH), and innovation and sophistication factors (INSOPF), become the inputs of the DEA model. 
In order to represent the level of human development within the studied countries, those criteria used in the HDI are used as the output of the DEA model. (Explanation to Prof. Parker: In DEA, you have inputs and outputs and the success of the DMU depends on its ability to transform as much inputs as possible into outputs. Therefore, we cannot say "from" above, we should say "of". The output of DEA is efficiency scores. It uses inputs and outputs as input to find efficiency of each DMU when, this case efficiency score is the actual output of DEA. Please refer to figure 1.). These criteria are: Life expectancy at birth (LIFEXP), combined gross enrolment ratio for primary, secondary, and tertiary schools (ENROLL), and GDP per capita (GDPCAP). Note that these represent the three well-accepted dimensions of human development: Health, education, and the economy. Input and output data were subsequently gathered from the WEF [26] and HDR [39], respectively.

Once the nations' rankings have been generated via the DEA, an ANN analysis is employed (in the second stage) to identify those indicators that appear to have the highest impact on stage 1 rankings. The relevant metric here is the nation's super-efficiency scores. Figure 1 presents a detailed view of the proposed methodology.

$<$ insert Figure 1 about here $>$

\subsection{Rationale for Use Data Envelopment Analysis and Artificial Neural Networks}

The most well-known and highly regarded approaches for measuring efficiency can be categorized into econometric models and mathematical programming. The former includes regression-based techniques which are generally stochastic in nature, where stochastic frontier analysis is one of the most widely applied. Mathematical programming approaches used for measuring efficiency include a wide range of nonparametric techniques that are largely nonstochastic, such as DEA and goal programming [40].

As is generally known, DEA is a method for measuring the relative efficiency of a group of operating units where the relative values of the variables are unknown [41]. It accommodates multiple inputs and outputs and can also include exogenously fixed environmental variables. DEA utilizes the fundamental concept of a production function. Further, since it uses linear programming (LP) as a nonparametric technique, assumptions regarding the statistical properties of its variables are not required [42].

In DEA, it is normal practice to assign relative importances to the competing explanatory factors prior to analysis. The inputs and outputs are then entered into the optimization 
algorithm but, as suggested, there is no built-in test of their appropriateness. Indeed, DEA does not require specification of a functional form to be fitted. If the true form is unknown, this feature of DEA could be advantageous, since it avoids the danger of fitting an inappropriate structure. If used carefully with large samples, DEA is effective at identifying possible explanations for apparently poor performance. These include crude indicators such as performance ratios which can provide a checklist of questions for management [43-44].

While the basic idea of DEA is well founded and clearly grounded in economic theory, the practicality of choosing appropriate inputs and outputs in the context of performance measurement is complex. Management opinion may not necessarily be given in the form of explicit identification of input/output factors; rather, it is often expressed in the more global sense of decision-making units (DMUs) being efficient or inefficient. In many circumstances, this form of expression of expertise can be a valuable input to a performance measurement exercise.

For the purposes of avoiding an inappropriate structure fit, in this paper, DEA is selected as the primary tool for comparing nations' capabilities of converting their competitiveness into the well-being of their citizens, i.e., the human development level. The main argument is that competitiveness is not important unless it is good for the nations' people. That is why, pillars measuring competitiveness are taken as inputs and the indicators of human development in health, education, and economy are used as outputs for the DEA in stage 1.

Charnes-Cooper-Rhodes' (CCR) [45] and Banker-Charnes-Cooper's (BCC) models [46] are the two founding DEA structures, where the former exhibits constant returns to scale (CRS) and the latter variable returns to scale (VRS). The VRS model was developed specifically to accommodate scale effects. However, when there are inherently no such effects, smaller and larger units will tend to be over-rated in efficiency as the model will envelop the data mode closely than would the CRS form [47].

In classical DEA, the DMUs are represented on a 0-1 scale, where efficient units score 1.0, while the less efficient score less than 1.0. The efficiency score of a DMU is measured by a combination of DEA-efficient DMUs, which form selected segments on the efficiency frontier. The efficient DMUs are generally not comparable amongst themselves. In order to avoid such incomparability of DMUs, a super-efficiency DEA model [48] was used in the 
current study. Hence it was possible to compare every nation, including those on the efficient frontier.

The other second stage technique used in this research is ANN analysis. In contract to DEA, this methodology forms a class of nonparametric models that acquire knowledge under conditions of noise and uncertainty, to perform generalization and abstraction, and to create their own knowledge by self-organization. The relationships in these models are generated implicitly and are; ideally, sufficiently general to interpolate accurately in high-dimensional input/output spaces. A multilayered feed-forward neural network with a back-propagation learning rule [49] is the most popular and widely applied of the many existing types of ANN analyses. Back-propagation calculates the difference between, on the one hand, the results calculated using the network weights and, on the other hand, the outputs in the training set, and feeds back the error to the network by adjusting the weights in a recursive fashion in order to minimize error. Network training is accomplished by seeking the set of values of the weights that minimizes an error function, such as the sum of the squares of the errors. Because of their nonparametric nature, ANNs can also serve as an evaluation mechanism for business decisions and prediction or classification heuristics [20].

\subsection{Theoretical Framework of Super-Efficiency Data Envelopment Analysis}

DEA is a data-oriented method for measuring and benchmarking the relative efficiency of peer decision-making units [45-50]. The efficient DMUs obtained in most DEA models like $\mathrm{CCR}$ and $\mathrm{BCC}$ cannot be compared. In order to provide an overall assessment of the performances of all DMUs, ranking DMUs in DEA became an interesting topic in the last decade. According to Li et al. [48], the most popular research stream about ranking the efficient DMUs is called super-efficiency. In this direction, researchers focused on ranking only DEA efficient DMUs based on the results obtained either from CCR or BCC models. The research in this area was first developed by Andersen and Petersen [52]. See Li et al. [48] for a brief review of the super efficiency models.

In this paper we used a generic super efficiency model. We assume that there are $n$ homogeneous DMUs such that all the DMUs use $m$ inputs $x_{i j}(i=1, \ldots, m)$ to produce $s$ outputs $y_{r j}(r=1, \ldots, s)$. It is also assumed that $X_{j}=\left(x_{i j}\right) \in \mathfrak{R}^{s_{x} n}$ is nonnegative. On the basis of classical output-oriented CCR model, an output-oriented super-efficiency model can be defined as follows: 
Maximize $\eta_{0}$, subject to

$$
\begin{aligned}
& x_{i 0}-\sum_{\substack{j=1 \\
j \neq 0}}^{n} \mu_{j} x_{i j} \geq 0 \quad i=1, \ldots, m, \\
& \eta_{0} y_{r 0}-\sum_{\substack{j=1 \\
j \neq 0}}^{n} \mu_{j} y_{r j} \leq 0 \quad r=1, \ldots, s, \\
& \mu_{j} \geq 0 \quad j=1, \ldots, n .
\end{aligned}
$$

Here $1 / \eta_{0}$ gives the super efficiency value for $\mathrm{DMU}_{0}$. This model gives the same score with the classical CCR model if the score is less than one. For the efficient DMUs, which has efficiency score of 1 , of the classical CCR model, the given model results with super efficiency scores that are greater than or equal to 1 . In this way, this model has two main benefits. Firstly it can be used to specify efficient DMUs. If the super efficiency value of DMU is greater than 1 then it is labeled as efficient DMU, otherwise it is called inefficient. Secondly, it can rank not only the inefficient DMUs but also the efficient DMUs.

In the subsequent stage, in order to analyze the basic indicators that play an important role in the super-efficiency scores of countries, an ANN is used, where the indicators are taken as inputs and the super-efficiency scores are taken as outputs.

\subsection{Theoretical Framework of Artificial Neural Network}

The basic idea behind using an ANN in this study was to specify the variables that have the highest weights in determining the efficiency score of the countries. To do this analysis, a feed-forward ANN with a back-propagation learning algorithm was used.

ANNs are nonparametric models whose estimation is based on stochastic nonlinear mathematical programming techniques [51]. They make no assumptions about the statistical properties of the data and the functional form of the underlying efficiency model. Moreover, they are not necessarily deterministic and can acquire knowledge under conditions of noise and uncertainty, to perform generalization and abstraction and to create their own knowledge. ANN techniques have been applied to a variety of problem areas and have, in many instances, provided superior results to conventional methods [53]. It is well known that ANNs show 
excellent performance on pattern recognition tasks. The literature, such as [54-56], suggests that the potential advantages of ANNs over statistical methods are: (i) ANNs perform better when extreme values exist; (ii) estimation by ANNs can be automated, whereas regression and autoregressive integrated moving average (ARIMA) models must be re-estimated periodically whenever new data arrives; and (iii) ANNs give better results when the data is nonlinear. It has been proven that a network with only one hidden layer is sufficient to approximate any continuous function. Therefore, ANNs might offer a viable alternative to econometric techniques. Moreover, neural networks are also better at capturing turning points. This is why an ANN was proposed in this study for selecting the most important criteria affecting countries' efficiency scores.

In multilayer neural networks, the inputs are connected to the outputs via hidden neurons instead of a direct connection. For this reason, in order to determine the characteristics of each input neuron and the strength of the connection between input $X_{i}$ and output $O_{i}$, several different weight measurement techniques can be used. One such measure proposed by Yoon et al. [57] is as follows:

$$
R S_{j i}=\frac{\sum_{k=0}^{n}\left(W_{k i} * U_{j k}\right)}{\sum_{i=0}^{m} \mid\left(\sum_{k=0}^{n}\left(W_{k i} * U_{j k}\right) \mid\right.}
$$

In this formula, $R S_{j i}$ is the strength of the connection between input $i$ and output $j, W_{k i}$ is the weight between hidden neuron $k$ and input neuron $i$, and $U_{j k}$ is the weight between output neuron $j$ and hidden neuron $k$. This statistic, in fact, is the ratio of the strength between input $i$ and output $j$ to the total strength of all neurons between the input and the output. The absolute value in the denominator is used to eliminate any negative relations between the input and output neurons. To increase the efficiency of the measure, the square of both the numerator and the denominator may be taken, as suggested by Onsel et al. [53]. The sum of the weights is set equal to 1 . In this research, the resulting modified formula was used as the basis of the analysis:

$$
R S_{j i}=\frac{\left[\sum_{k=0}^{n}\left(W_{k i} * U_{j k}\right)\right]^{2}}{\sum_{i=0}^{m}\left[\sum_{k=0}^{n}\left(W_{k i} * U_{j k}\right)\right]^{2}}
$$


The weights between the input and hidden neurons, and between the hidden and output neurons determine the performance of the ANN in executing multidimensional nonlinear regression. For this reason, weight analysis of an ANN, such as the one in this study, can give information about the impact of input neurons on output neurons.

\section{Evaluation of Selected Countries Based on Data Envelopment Analysis}

In this study, in order to compare the countries of similar scale, those representing $90 \%$ of the world in terms of both world population and total world GDP were selected. For this reason, among the countries evaluated by the WEF (104 countries), only those having a population of over 25 million and/or a GDP level over 200 billion United States (US) dollars were chosen for analyses. Among the selected countries, 17 constituted the largest economies in the world in terms of purchasing power parity (PPP). These were the Group of Seven (G7) industrialized countries (US, Japan, Germany, United Kingdom [UK], France, Italy, and Canada), as well as Spain, Australia, and Korea, and the seven largest emerging-market economies, referred to collectively as "E7" (China, India, Brazil, Russia, Indonesia, Mexico, and Turkey) [58]. The selected countries also include 20 Organisation for Economic Cooperation and Development (OECD) countries, 12 European countries that are members of the European Union, and four European countries that are not members of the European Union (Turkey, Russia, Norway, and Ukraine). There were also 10 countries from Africa, 10 countries from Asia, 6 from South America, 2 from North America, and Australia. The first column of Table 1 gives a complete list of the selected countries.

\section{$<$ Insert Table 1 about here $>$}

\subsection{Ranking of the Countries}

As mentioned in Section 3, the inputs of the DEA model were the BASREQ, EFFENH, and INSOPF; the outputs were LIFEXP, ENROLL, and GDPCAP.

The application of DEA presents a range of issues relating to the homogeneity of the units under assessment, the input/output set used, the measurement of those variables, and the weights attributed to them in the analysis. Each of these issues can present practical difficulties in applying DEA. When constructing a DEA model, these assumptions should be considered. To avoid the pitfalls highlighted by Dyson et al. [47], in this research, all the 
selected inputs are index measures while the outputs are volume measures. In order not to mix indices with volume measures for the outputs, the literacy rate indicator of the HDI was omitted. In fact ENROLL can be accepted as sufficient to measure the education level of a country. To mix indices, often associated with performance measures, with activity levels, which are volume measures is generally not suitable in DEA. This may be acceptable if all the inputs (and outputs) are of the same kind, as is proposed in this study [47].

The original assumption on the measurement scales of the inputs and outputs is that they should conform to ratio scale. This may be an unnecessarily strong assumption, but certainly an interval scale is an assumption of many DEA models [47]. In this study the inputs and one of the outputs, namely ENROLL, are measured in interval scale while the other outputs (i.e. LIFEXP and GDPCAP) are measured in ratio scale, which satisfies the assumption of measurement scales.

The inputs, BASREQ, EFFENH, and INSOPF, are generated from 177 criteria, which are the hard data and survey data used in the WEF [26] report. As the survey data are in 1-7 Likert scale and the hard data are transformed to the same scale; the resulting indices are all in 1-7 scale. Therefore they can be considered as index variables.

As far as the outputs are concerned, LIFEEXP data are based on the estimates gathered from World Population Prospects, the official source of United Nations population estimates and projections. ENROLL data are produced by the United Nations Educational, Scientific and Cultural Organization (UNESCO) Institute for Statistics based on enrolment data collected from national governments and population data from the United Nations Population Division's report. The gross enrolment ratios are calculated by dividing the number of students enrolled in all levels of schooling (excluding adult education) by the total population in the official age group corresponding to these levels. ENROLL can be over $100 \%$ due to the inclusion of over-aged and under-aged pupils/students because of early or late entrants, and grade repetition. That's why this variable can be considered as a volume measure. GDPCAP (PPP US\$) data for the HDI are provided by the World Bank based on price data from the latest International Comparison Program surveys and GDP in local currency from national accounts data. PPPs for these countries are estimated directly by extrapolating from the latest benchmark results. For countries not included in the International Comparison Program surveys, estimates are derived through econometric regression. For countries not 
covered by the World Bank, PPP estimates provided by the Penn World Tables of the University of Pennsylvania are used [59].

The input and output data used are based on WEF and HDI, respectively, and are accepted as reliable. In fact, the WEF data (i.e., the inputs) used in this study represent the best available estimates from various national authorities, international agencies, and private sources at the time the WEF [26] Report was prepared (July/August 2004). The WEF scores are generated from 181 indicators, 155 of which are the survey data. It is generally argued that the measurement of qualitative factors is highly subjective and using such data to characterize qualitative variables may result in an unfair DEA evaluation. However, the WEF survey data cover a large number of respondents, which reduces the effect of subjectivity on the measurement process. In fact, in the countries evaluated in this research the average number of respondents is 289.14 .

The data of HDI (i.e., the outputs) on the other hand, are gathered from major statistical agencies. These are often specialized agencies of the United Nations working on issues such as health, World Health Organization (WHO); education, UNESCO Institute for Statistics; and labor market statistics, International Labor Organization (ILO) [59]. Despite some data availability problems, it is accepted that the HDI scores are internationally comparable.

Table 1 shows the input and output values for the selected countries. Equation (2) in Section 3.2 is used to calculate the super efficiency score of each country. In order to find the super efficiency scores for the countries, the linear programming model given in equation (2) is solved individually for every country. The efficiency score of the selected country is calculated by taking multiplicative inverse of the objective value $\left(\eta_{0}\right)$ of the linear program as $1 / \eta_{0}$. While solving the models the following considerations are made:

$\mathrm{DMU}_{0}:$ the selected country,

$j$ (index for the homogeneous DMUs, which are countries), $j=1,2 \ldots, 45$,

$i$ (index for the inputs) $=1$ (BASREQ), 2 (EFFENH), and 3 (INSOPF),

$\mathrm{s}($ index for the outputs) $=1$ (LIFEXP), 2 (ENROLL) and 3 (GDPCAP),

$x_{i j}$ (input values of the DMUs) are the second to fourth columns of Table 1, 
$y_{r j}$ (output values of the DMUs) are the fifth to seventh columns of Table 1.

The results are given in Table 2.

$<$ Insert Table 2 about here $>$

The super efficiency scores given in Table 2 can be interpreted in such a way that the countries having scores greater than or equal to 1.0 are efficient countries. They use their competitiveness power efficiently for human development of their citizens. On the other hand the inefficient countries, which have scores less than 1.0, have relatively low human development levels compared to efficient countries according to their competitiveness levels.

When the DEA results were analyzed (see Table 2), Algeria, Argentina, Australia, Belgium, Italy, Norway, Poland, UK, US, and Venezuela were found to be efficient (i.e., they had a score $\geq 1$ ). It is noteworthy that among these efficient countries, Algeria, Argentina, Italy, Poland, and Venezuela were found to have low ranks for both the WEF and HDI indices, indicating that the human development performance of these nations except for Algeria is relatively high compared with their competitiveness. In fact, the same argument is valid for Algeria because although its WEF rank is not very low $\left(28^{\text {th }}\right)$, mainly due to its relatively high BASREQ level, its EFFENH and INSOPF levels are very low.

In contrast, Canada, France, Germany, the Netherlands, Sweden, Switzerland, and Taiwan, which held the top ranks for both the WEF and HDI indices, had lower DEA ranking, indicating they are not efficiently using their competitiveness or their potential to improve their human development efficiency.

To analyze the countries according to their geographical location as well as their international economic organization memberships, they were grouped as given in Table 3. Similarities or differences among groups are evaluated below.

$<$ Insert Table 3 about here $>$

In Table 3, average scores of countries in different groups are given. Note that some countries may belong to more than one group; for instance, Turkey is in Europe geographically and at the same time it is both an E7 and an OECD country. 
According to the DEA results for the groups of countries, the results for the South American countries (Argentina, Brazil, Colombia, Mexico, Peru, and Venezuela) are unexpectedly high (1.021), all three of their input values being lower than the total average and their LIFEXP and ENROLL scores higher than or equal to the total average, indicating they produce average human development with low competitiveness.

African countries, on the other hand, have the lowest average, as expected. They have low input values as well as low outputs. Africa, Asia, and the E7 countries have lower average DEA scores than the total average, being dramatically lower than the other groups. North America, Europe, and the E7 countries have similar high averages.

\subsection{Projection and Slack-Based Evaluation}

One way of making a judgment of a country's relative efficiency is to use a subjection linear frontier. Countries can become more efficient than their current level after they are projected onto a frontier, the result being called a projection. In this study, projections of outputs for different country groups were calculated to emphasize the potential output values obtainable with the current inputs. In other words, the projection analysis is conducted in here, to find out what is the potential human development level of the inefficient countries according to their current competitiveness level.

As can be seen in Table 4, Africa has the highest potential of improvement for all outputs. For instance, African countries, using the same competitiveness level (i.e., inputs), can increase their average GDPCAP value by $290 \%$ (from 3,135 to 12,234). For LIFEXP, Europe can increase the life expectancy of its citizens by $9.31 \%$ (from 76.5 to 83.6), and North America can do so by $5.62 \%$ (from 78.7 to 83.12). In contrast, South America's current level of LIFEXP is greater than the projection that can be generated from the current level of inputs. In fact, this shows that the actual level is unexpectedly high.

$<$ Insert Table 4 about here $>$

For ENROLL, the Asian and African countries are projected to reach a much higher level than the current situation. Interestingly, the E7 countries are also found to have a potential to increase their ENROLL value by $18.04 \%$ (74.14 to 87.52) (see Table 4).

In terms of GDPCAP, besides Africa, the Asian and the E7 countries were also found to have great potential for increase ( $97 \%$ and $145 \%$, respectively). 
Based on the projection analysis, it can be seen that the G7 and OECD countries have relatively higher potential of increasing life expectancy compared to the other outputs. On the other hand, for the E7 countries, the potential of increasing their GDP per capita is especially relatively much higher. Among the G7 countries Italy, UK, and the US are observed to be efficient in converting their competitiveness into human development, while Canada, France, Japan, and Germany have relatively lower ranks.

In DEA, the slack is the difference between the value of the projection and the actual value, and is often used to provide interpretations of the input and output variables.

In the countries evaluated in this research, it was found that LIFEXP is used efficiently by $69 \%$ of the countries. Therefore, a small increase in life expectancy values can contribute to an increase in the DEA score. On the other hand, economic power (GDPCAP) and education (ENROLL) are used efficiently by $58 \%$ and $56 \%$ of the countries, respectively (see Figure 2 ).

$<$ Insert Figure 3 about here $>$

\subsection{Detailed Analysis of E7 Countries and Turkey}

In recent years there has been an increasing focus on the opportunities and challenges posed by China, India, and other emerging-market economies to the established advanced economies of the US, Europe, and Japan. For this reason, it was decided in this study to analyze the DEA scores of the E7 countries in detail. The evaluation of the results showed that among the E7 countries, India was ranked last, followed by China and Indonesia (Table 5), with Turkey in the middle position. The highest ranked countries are Brazil and the Russian Federation. Interestingly, none of the E7 countries are efficient.

$<$ Insert Table 5 about here $>$

The projections show that among the inputs necessary to reach a specific output level, BASREQ is a critical variable. In fact, even a small decrease in the BASREQ value can increase the efficiency score of a country. On the other hand, when evaluated from an output perspective, it can be said that for the same level of inputs, countries have a high potential of increasing their outputs (human development). In particular, China, Indonesia, and India have a very high potential of increasing their GDPCAP levels. For instance China can increase its GDPCAP value by $275 \%$ with the same input (i.e. competitiveness level) according to the projections given in the last column of Table 5. In fact, those three countries also have the 
highest projection levels for other outputs. Turkey, following China, Indonesia, and India, is the fourth in terms of potential to increase the GDP per capita level. The potential increases of Brazil and Mexico are considerably lower than the others.

The peer countries for Turkey were found to be Italy and Venezuela. In fact, when the input and output values of those countries are compared with those of Turkey, it can be seen that although the input values of Venezuela are comparatively very low with respect to Turkey's, its output value is much higher. On the other hand, both the input and output values of Italy are higher than those of Turkey. According to these results, since it would be illogical to expect Turkey to reduce its current competitiveness level, it would be more appropriate for Turkey to take Italy as its peer country and seek to increase its level of outputs using its current input levels.

When the projections for inputs and outputs are analyzed, it was seen that, for Turkey, BASREQ and EFFENH were critical in the realization of any improvement that could be obtained in the efficiency level (Table 5). Additionally, with its current competitiveness, Turkey has the potential to increase its LIFEXP by $12.59 \%$, its ENROLL by $19.52 \%$, and its GDPCAP by $95.46 \%$. In other words, in the present situation, Turkey is under-using its current competitiveness to improve its economical level in particular.

\section{Determination of Factors Affecting Super-Efficiency Scores Using ANNs}

In order to specify the criteria that have the highest impact in determining the super-efficiency score of the countries, a feed-forward ANN analysis was conducted with a back-propagation learning algorithm. For this purpose, the WEF scores and HDI scores, namely, BASREQ, EFFENH, INSOPF, LIFEXP, ENROLL, and GDPCAP were used as inputs, and the super efficiency score was used as the output of the ANN. While applying the ANN on the problem, input data was normalized within a 0.1-0.9 scale based on the suggestion of Tang and Fishwick [49]. The number of hidden neurons to be used in the hidden layer was specified according to Masters [50], who suggests beginning with a very small number, such as 2, and test the resulting ANN model in order to find one that will provide the lowest level of error. The aim is to stop the learning process whenever memorizing begins. The best way of doing this is to stop the learning process at specific intervals, analyze the results for the test data, and continue with the learning process if the error term continues to decrease for the test data. 
Additionally, as was suggested by Tang and Fishwick [60], the ANN was run ten times for each different number of hidden neurons.

In order to avoid local optimality, a back-propagation algorithm with momentum was used; the momentum and learning rate was taken as 0.9 and 0.01 , respectively. The analysis showed that the best values were obtained for four hidden neurons. The training and test performance values (mean square error) were found to be 0.00289 and 0.006 , respectively, after 1500 epochs of training. Figure 3 shows the training and test performance of the ANN.

\section{$<$ Insert Figure 3 about here $>$}

As can be seen from Table 6, according to the ANN results, the most important criterion affecting a country's super-efficiency score is GDPCAP, with a value of $54.9 \%$, followed by LIFEXP and EFFENH, with values of $24.5 \%$ and $10.1 \%$, respectively. It is interesting to note, therefore, that the countries that are efficient in converting their competitiveness into improvement in their human development level are those which have high GDPCAP and LIFEXP levels, which are in fact, the outputs of the DEA. This indicates that, in order to increase the efficiency scores, the countries should especially focus on increasing these two outputs. On the other hand, the ANN results also show that high BASREQ and ENROLL levels do not play any effective role in improving the efficiency score.

$<$ Insert Table 6 about here $>$

\section{Conclusions and Further Suggestions}

Economic welfare can arise as a consequence of an excellent national market performance while the international performance is average and high economic welfare can a signal for economic decline [61] or decreasing competitiveness so that welfare is an ambivalent indicator. Krugman [61] argues that the obsession with competitiveness has led to a neglect of what really matters for improving national economic performance and living standards which is domestic productivity growth.

In this study, the capability of countries to convert their competitiveness into better lives for their people has been analyzed through a two-stage study based on DEA and ANN analysis. In the first stage, the scores of the WEF related to BASREQ, EFFENH, and INSOPF were used as the inputs of the DEA, while the HDI scores were taken as the output. The results of the DEA gave super-efficiency scores for the countries, taken as the output of the ANN where 
the inputs were the WEF and HDI scores. Consequently, the impact of the indicators for the super-efficiency score was revealed.

According to the DEA results, DEA scores of the European and North American countries are lower than expected. Most of the top ranked countries according to WEF and HDI are European and North American (12 of the top 15 countries at WEF rank and 13 of the 15 countries at HDI rank are in this group). Therefore they are also expected to be at the top according to their ability to convert their competitiveness to better living conditions. However it is necessary to underline that, countries such as United States, United Kingdom, or France developed their education systems in the $19^{\text {th }}$ century. In Asia, Japan followed a relatively similar pattern. That may be the basic reason of their relatively lower rank in superefficiency scores. Thus it can be concluded that these countries are not currently using their high competitiveness level to increase their human development level due to the fact that they have already reached a maturity level in this respect.

In the E7 countries, the low DEA values are compatible with the title "emerging" designated to these countries. In fact, these countries show improvements in terms of competitiveness but do not experience the same performance in converting this competitiveness power into human development, although this conversion could be realized in the medium or long term. When analyzed with this logic, it can be seen that among the emerging countries, China, India, and Indonesia in particular can be considered promising according to the projection analysis. If the same type of analysis is conducted for the other countries, it can be seen that Morocco, South Africa, and Taiwan have the potential of obtaining higher human development levels because their WEF rankings are relatively much higher than their HDI rankings.

Finally, the ANN results show that the most important criteria affecting a country's efficiency score are GDP per capita and life expectancy. Focusing on these factors can have significant effect on increasing the DEA score.

In this study, the proposed methodology was applied using attribute values for the year 2004 published by the [26]. However, the method could be used to analyze performance over several years using procedures such as window analysis and the Malmquist Productivity Index, followed by times-series analysis of country performance to analyze the evolution of countries over the period. Additionally, the use of the three dimensions of the WEF competitiveness index as the three inputs assumes that all sectors within a nation are at the 
same stage concurrently. Therefore, further improvement of this work could be a sector-based evaluation among the countries or comparison of different sectors within a country.

Such research could be improved further by putting lower and upper bounds on some of the inputs, as it may not be very realistic to believe that an infinite reduction or an unlimited increase could be realized in some of the attributes in an attempt to generate a greater efficiency score for a country. Finally, imposing ratios between certain inputs may also be more realistic.

In this study, the dynamic structure of the problem was not taken into account. However, the connection between human development and competitiveness is a two-way interaction. For example, education is an important contributor to technological capability and technical change in industry. Similarly, improved health has direct effects on labor productivity, especially among poorer countries. The impact of education on the nature and growth of exports, which, in turn, affects the aggregate growth rate, is another way in which human development influences macroeconomic performance. Therefore, a dynamic model with feedback to analyze these interrelationships through time lags would be useful to account for e.g. the impact of education on economic growth.

In the further step of the research the same methodology will be applied to WEF 2006-2007 and HDI 2007 data and the evolution or degradation of the countries will be analyzed based on panel data. 


\section{REFERENCES}

1. Kogut B. Country patterns in international competition: appropriability and oligopolistic agreement. In: Hood N, Vahlne, JE, editors. Strategies in global competition, New York: Wiley; 1988, p. 315-340.

2. Porter ME. The competitive advantage of nations. London: Macmillan; 1990.

3. Dunning JH. The globalization of firms and the competitiveness of countries. In: Dunning JH, Kogut B, Blomström M, editors. Globalization of firms and the competitiveness of nations, Lund: Lund University Press; 1990, p. 9-57.

4. Dunning JH. The globalization of business: the challenge of the 1990s. London: Routledge; 1993.

5. Davies A, Quinlivan G. A panel data analysis on the impact of trade on human development. Journal of Socio-Economics 2006;35(5):868-876.

6. Artto EW. Relative total costs-an approach to competitiveness measurement of industries. Management International Review 1987;27:47-58.

7. Fagerberg J, Srholec M, Knell M. The competitiveness of nations: why some countries prosper while others fall behind. World Development 2007;35(10):1595-1620.

8. European Commission. A Pro-Active Competition Policy for a Competitive Europe. COM 293 final. Brussels: April 20 2004. http://ec.europa.eu/competition/publications/proactive/en.pdf

9. WEF (World Economic Forum). The global competitiveness report 2006-2007. New York: Palgrave Macmillan; 2006.

10. Boltho A. The assessment: international competitiveness. Oxford Review of Economic Policy (1996);12(3):1-16.

11. Fagerberg J. Technology and competitiveness. Oxford Review of Economic Policy 1996;12(3):39-51.

12. Lall S. Competitiveness indices and developing countries: an economic evaluation of the global competitiveness report. World Development 2001;29:1501-1525. 
13. Akhter, S.H. Is globalization what it's cracked up to be? Economic freedom, corruption, and human development. Journal of World Business 2004:39:283-295.

14. Toulmin S. The ambiguities of globalization. Futures 1999;31:905-912.

15. Mundle S. Introduction to Special Section of World Development on Financing Human Development. World Development 1998;26(4):657-658.

16. Costantini V, Monni S. Environment, human development and econometric growth. Ecological Economics 2008;64(2):867-880.

17. Sagar AD, Najam A. The human development index: a critical review. Ecological Economics 1998;25:249-264.

18. Mitschke A. The Influence of National Competition Policy on the International Competitiveness of Nations, Heidelberg: Physica-Verlag; 2008.

19. UNDP (United Nations Development Program) Human Development Reports, 2008a http:/hdr.undp.org/en/humandev/

20. Zanakis SH, Becerra-Fernandez I. Competitiveness of nations: a knowledge discovery examination. European Journal of Operational Research 2005;166(1):185-211.

21. Golany B, Thore S. The economic and social performance of nations: efficiency and returns to scale. Socio-Economic Planning Sciences 1997;31(3):191-204.

22. Sala-i-Martin X, Artadi EV. The global competitiveness index. In: WEF (World Economic Forum). The global competitiveness report 2004-2005. New York: Oxford University Press for the World Economic Forum; 2004, p. 3-18.

23. http://www.imd.org/research/publications/wcy/index.cfm

24. McArthur JW, Sachs JD. The growth competitiveness index: measuring technological advancement and the stages of development. In: WEF (World Economic Forum), The global competitiveness report 2001-2002. New York: Oxford University Press for the World Economic Forum; 2001, p. 28-51.

25. Blanke J, Lopez-Claros A. The growth competitiveness index: assessing countries' potential for sustained economic growth. In: WEF (World Economic Forum), The global 
competitiveness report 2004-2005. New York: Oxford University Press for the World Economic Forum; 2004, p. 3-18.

26. WEF (World Economic Forum). The global competitiveness report 2005-2006. New York: Palgrave Macmillan; 2005.

27. Ranis G, Stewart F, Ramirez A. Economic growth and human development. World Development 2000;28(2):197-219.

28. Anand S, Sen A. Human development and economic sustainability. World Development 2000;28(12):2029-2049.

29. Aiginger, K. A framework for evaluating the dynamic competitiveness of countries. Structural Change and Economic Dynamics 1998;9:159-188.

30. UNDP (United Nations Development Program). Human Development Report. New York: Oxford University Press; 1990.

31. UNDP (United Nations Development Program) Human development Index, Technical note; 2008 , http://hdr.undp.org/en/media/hdr 20072008 tech note 1.pdf

32. Winston, W.L., Operations Research: Applications and Algorithms. Duxbury Press 2003.

33. Onsel S, Ulengin F, Ulusoy G, Aktas E, Kabak O, Topcu Y.I. A new perspective in competitiveness of nations. Socio-Economic Planning Sciences 2008;42(4);221-246.

34. Oral M, Chabchoub H. On the methodology of the world competitiveness report. European Journal of Operational Research 1996;90(3):514-535.

35. Oral M, Chabchoub H. An estimation model for replicating the rankings of the world competitiveness report. International Journal of Forecasting 1997;13:527-537.

36. Oral M, Cinar U, Chabchoub $\mathrm{H}$. Linking industrial competitiveness and productivity at the firm level. European Journal of Operational Research 1999;118(2):271-277.

37. Despotis DK. Measuring human development via data envelopment analysis: the case of Asia and the Pacific. Omega 2005;33:385-390. 
38. Neumayer E. The human development index and sustainability-a constructive proposal. Ecological Economics 2001;39:101-114.

39. UNDP (United Nations Development Program) Human Development Report; 2005, http://www.sd.undp.org/HDR/HDR05e.pdf

40. Fried HO, Lovell CAK, Schmidt SS. The measurement of productive efficiencytechniques and applications. New York: Oxford University Press; 1993.

41. Emrouznejad A, Parker BR, Tavares G. Evaluation of research in efficiency and productivity: A survey and analysis of the first 30 years of scholarly literature in DEA. Socio-Economic Planning Sciences 2008:42(3):151-157.

42. Retzlaff-Roberts D, Chang CF, Rubin RM. Technical efficiency in the use of health care resources: a comparison of OECD countries. Health Policy 2004;69(1):55-72.

43. Cubbin J, Tzanidakis G. Regression versus data envelopment analysis for efficiency measurement: an application to the England and Wales regulated water industry. Utilities Policy (1998);7(2):75-85.

44. Burki A, Terrell D. Measuring production efficiency of small firms in Pakistan, World Development 1998;26(1):155-169.

45. Charnes A, Cooper WW, Rhodes E. Measuring the efficiency of decision making units. European Journal of Operational Research (1978);2(6):429-444.

46. Banker RD, Charnes A, Cooper WW. Some models for estimating technical and scale efficiencies in data envelopment analysis. Management Science 1984;30:1078-1092.

47. Dyson RG, Allena R, Camanhob AS, Podinovskia VV, Sarricoa CS, Shalea EA. Pitfalls and protocols in DEA. European Journal of Operational Research 2001;132(2):245-259.

48. Li S, Jahanshahloo GR, Khodabakhshi M. A super-efficiency model for ranking efficient units in data envelopment analysis. Applied Mathematics and Computation 2007;184(2):638-648.

49. Smith KA, Gupta JND. Neural networks in business: techniques and applications for the operations researcher. Computers \& Operations Research 2000;27:1023-1044. 
50. Cooper WW, Seiford LM, Tone K. Data envelopment analysis: a comprehensive text with models, Applications, References and DEA-Solver Software. Boston: Kluwer Academic Publishers; 2000.

51. Costa V, Markellos RN. Evaluating public transport efficiency with neural network models. Transportation Research-C 1997;5(5):301-312.

52. Andersen, P., Petersen, N.C. A Procedure for Ranking Efficient Units in Data Envelopment Analysis. Management Science 1993;39(10):1261-1264.

53. Onsel S, Ulengin F, Ulengin B. A dynamic approach to scenario analysis: the case of Turkey's inflation estimation. European Journal of Operational Research 2004;158(1):124-145.

54. Swanson NR, White H. A model selection approach to real-time macroeconomic forecasting using linear models and artificial neural networks. Review of Economics and Statistics 1997;79:540-550.

55. Boznar M, Lesjak M, Mlakar P. A neural network-based method for short-term predictions of ambient $\mathrm{SO}_{2}$ concentrations in highly polluted industrial areas of complex terrain. Atmospheric Environment, Part B, Urban Atmosphere 1993;27(2):221-230.

56. Hwarng HB, Ang HT. A simple neural network for ARMA (p, q) time series. Omega 2001;29:319-333.

57. Yoon Y, Swales G, Margavio TM. A comparison of discriminant analysis versus artificial neural networks. Journal of Operational Research Society 1993;44(1):51-60.

58. Hawksworth J. The World in 2050: How big will the major emerging market economies get and how can the OECD compete? PricewaterhouseCoopers UK Economic Outlook; 2006, p. 21-31.

59. UNDP (United Nations Development Program) Human Development Report 2006: Beyond scarcity: power, poverty, and global water crisis, http://hdr.undp.org/hdr2006/report.cfm

60. Tang Z, Fishwick PA. Feed forward neural nets as models for time series forecasting. ORSA Journal on Computing 1993;5(4):374-385. 
61. Krugman P. Competitiveness: A dangerous obsession. Foreign Affairs 1994;73(2):28-44.

62. Masters T. Practical neural network recipes in C++. USA: Academic Press; 1993. 


WEF Scores
- Basic requirements
- Efficiency enhancers
- Innovation and sophistication factors

\section{HDI Scores}

- Life expectancy at birth

- Combined gross enrollment ratio for primary, secondary and tertiary schools - GDP / capita

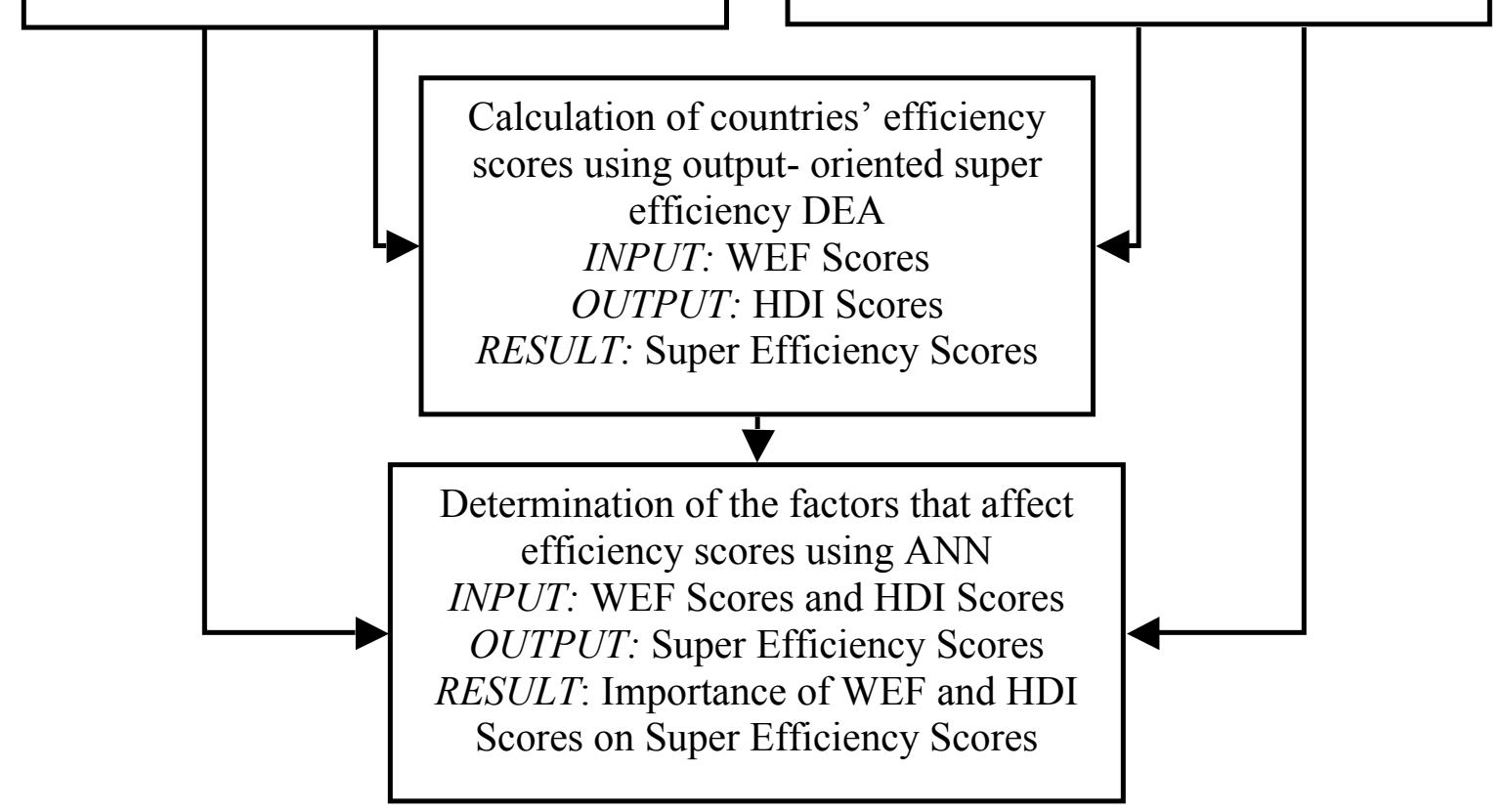

Figure 1 Framework of proposed methodology

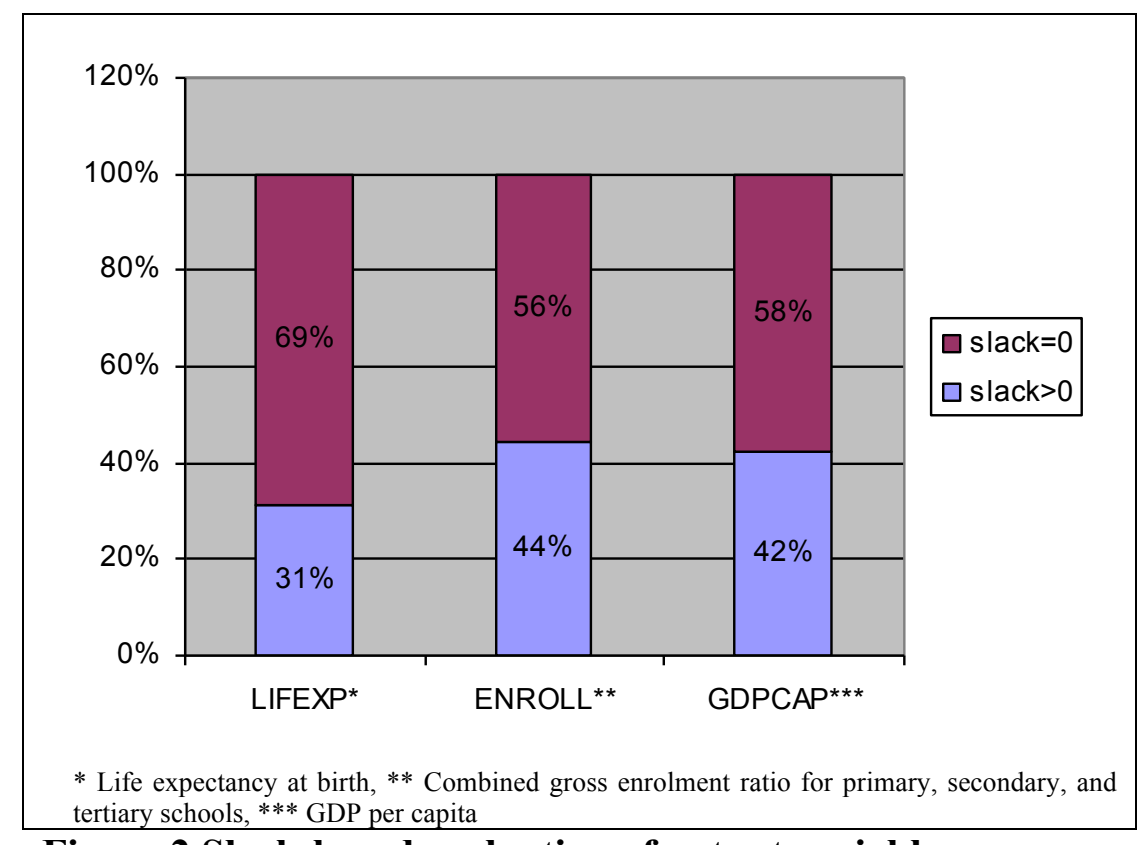

Figure 2 Slack-based evaluation of output variables 


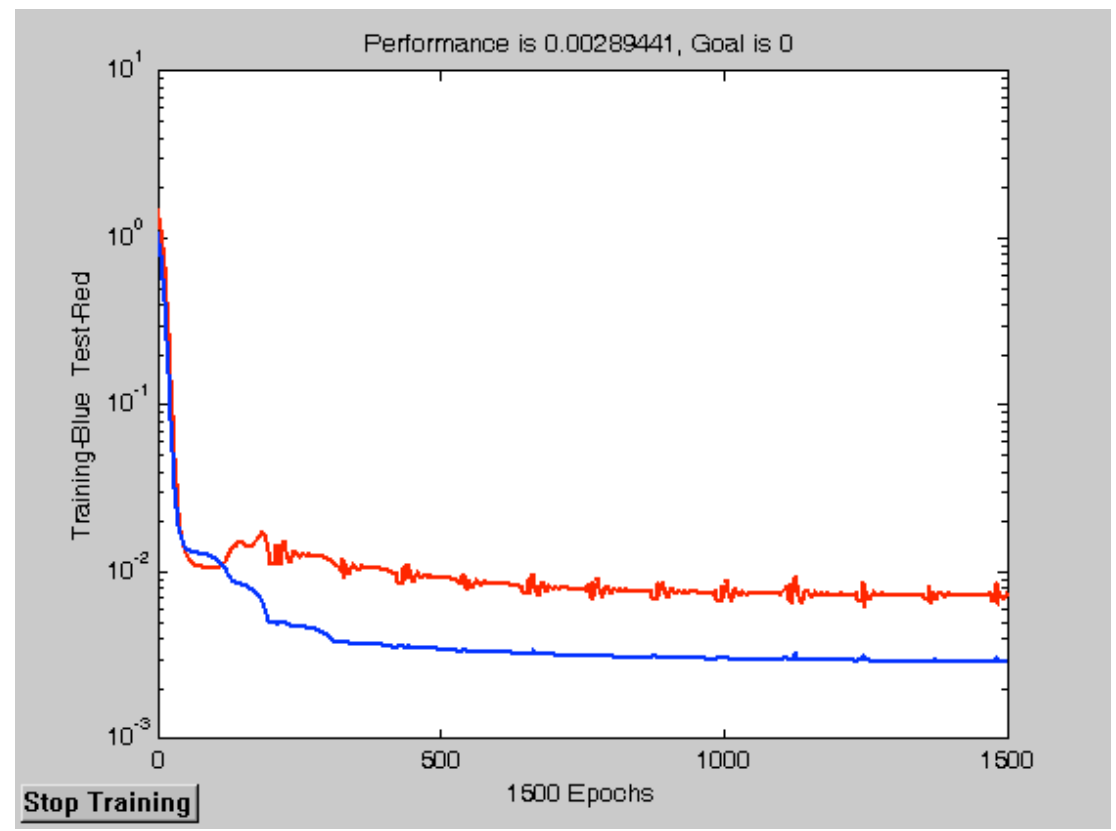

Figure 3 Training and test performance of ANN 
Table 1 Selection criteria of countries and data used in DEA

\begin{tabular}{|c|c|c|c|c|c|c|}
\hline \multirow[b]{2}{*}{ Country } & \multicolumn{3}{|c|}{ Input Data } & \multicolumn{3}{|c|}{ Output Data } \\
\hline & BASREQ & EFFENH & INSOPF & LIFEXP & ENROLL & GDPCAP \\
\hline Algeria & 4.71 & 2.70 & 2.50 & 71.1 & 74 & 6248 \\
\hline Argentina & 4.44 & 2.96 & 2.81 & 74.5 & 95 & 11586 \\
\hline Australia & 5.70 & 4.28 & 4.04 & 80.3 & 116 & 29143 \\
\hline Austria & 5.61 & 4.13 & 4.11 & 79.0 & 89 & 29972 \\
\hline Bangladesh & 3.81 & 2.63 & 2.41 & 62.8 & 53 & 1786 \\
\hline Belgium & 5.51 & 4.12 & 4.14 & 78.9 & 114 & 28396 \\
\hline Brazil & 4.39 & 3.51 & 3.55 & 70.5 & 91 & 7767 \\
\hline Canada & 5.58 & 4.30 & 4.23 & 80.0 & 94 & 30463 \\
\hline China & 4.85 & 3.59 & 3.43 & 71.6 & 69 & 4995 \\
\hline Colombia & 4.15 & 3.10 & 3.00 & 72.4 & 71 & 6784 \\
\hline Denmark & 5.99 & 4.55 & 4.42 & 77.2 & 102 & 30588 \\
\hline Egypt & 4.67 & 3.23 & 3.18 & 69.8 & 74 & 3950 \\
\hline Ethiopia & 3.42 & 2.35 & 2.23 & 47.6 & 36 & 716 \\
\hline France & 5.49 & 4.15 & 4.30 & 79.5 & 92 & 27327 \\
\hline Germany & 5.75 & 4.27 & 4.74 & 78.7 & 89 & 27609 \\
\hline India & 4.53 & 3.60 & 3.69 & 63.3 & 60 & 2909 \\
\hline Indonesia & 4.56 & 3.28 & 3.27 & 66.8 & 66 & 3364 \\
\hline Italy & 4.56 & 3.48 & 3.48 & 80.1 & 87 & 27050 \\
\hline Japan & 5.35 & 4.26 & 4.94 & 82.0 & 84 & 28162 \\
\hline Kenya & 3.72 & 3.01 & 3.03 & 47.2 & 52 & 1035 \\
\hline Korea & 5.30 & 3.87 & 3.87 & 77.0 & 93 & 17908 \\
\hline Mexico & 4.47 & 3.21 & 3.02 & 75.1 & 75 & 9136 \\
\hline Morocco & 4.70 & 3.27 & 3.14 & 69.7 & 58 & 4012 \\
\hline Netherlands & 5.59 & 4.36 & 4.32 & 78.4 & 99 & 29412 \\
\hline Nigeria & 4.08 & 2.97 & 3.07 & 43.4 & 64 & 1024 \\
\hline Norway & 5.96 & 4.25 & 4.01 & 79.4 & 101 & 37063 \\
\hline Pakistan & 3.78 & 2.91 & 2.94 & 63.0 & 35 & 1971 \\
\hline Peru & 4.19 & 3.00 & 2.64 & 70.0 & 87 & 5267 \\
\hline Philippines & 4.03 & 3.11 & 2.84 & 70.4 & 82 & 4321 \\
\hline Poland & 4.25 & 3.13 & 2.99 & 74.3 & 90 & 11623 \\
\hline Russian & & & & & & \\
\hline Federation & 4.42 & 3.18 & 3.14 & 65.3 & 90 & 9195 \\
\hline South Africa & 4.76 & 3.63 & 3.60 & 48.4 & 78 & 10492 \\
\hline Spain & 5.08 & 3.79 & 3.53 & 79.5 & 94 & 22264 \\
\hline Sweden & 5.76 & 4.45 & 4.69 & 80.2 & 114 & 26656 \\
\hline Switzerland & 5.88 & 4.45 & 4.61 & 80.5 & 90 & 30186 \\
\hline Taiwan & 5.31 & 4.38 & 4.44 & 74.0 & 94 & 24560 \\
\hline Tanzania & 3.47 & 2.84 & 2.73 & 46.0 & 41 & 611 \\
\hline Thailand & 4.90 & 3.57 & 3.31 & 70.0 & 73 & 7580 \\
\hline Turkey & 4.41 & 3.10 & 3.08 & 68.7 & 68 & 6749 \\
\hline Uganda & 4.02 & 3.01 & 2.87 & 47.3 & 74 & 1471 \\
\hline Ukraine & 4.18 & 2.90 & 3.03 & 66.1 & 86 & 5472 \\
\hline United Kingdom & 5.48 & 4.61 & 4.38 & 78.4 & 123 & 27106 \\
\hline United States & 5.5 & 5.02 & 5.18 & 77.4 & 93 & 37352 \\
\hline Venezuela & 4.16 & 2.77 & 2.64 & 72.9 & 75 & 4909 \\
\hline Vietnam & 4.48 & 2.95 & 2.63 & 70.5 & 64 & 2490 \\
\hline AVERAGE & 4.78 & 3.56 & 3.52 & 70.20 & 81.09 & 14415 \\
\hline
\end{tabular}


Table 2 Results of DEA

\begin{tabular}{|c|c|c|c|c|}
\hline DMU & $\begin{array}{l}\text { WEF } \\
\text { Rank }\end{array}$ & $\begin{array}{l}\text { HDI } \\
\text { Rank }\end{array}$ & $\begin{array}{c}\text { DEA } \\
\text { Score } \\
\end{array}$ & $\begin{array}{c}\text { Super } \\
\text { Efficiency } \\
\text { Rank } \\
\end{array}$ \\
\hline Norway & 10 & 1 & 1.189 & 1 \\
\hline Italy & 26 & 14 & 1.167 & 2 \\
\hline Argentina & 36 & 19 & 1.115 & 3 \\
\hline United States & 1 & 7 & 1.092 & 4 \\
\hline Venezuela & 40 & 26 & 1.079 & 5 \\
\hline United Kingdom & 6 & 11 & 1.077 & 6 \\
\hline Algeria & 28 & 32 & 1.040 & 7 \\
\hline Australia & 12 & 2 & 1.025 & 8 \\
\hline Poland & 33 & 20 & 1.022 & 9 \\
\hline Belgium & 15 & 6 & 1.018 & 10 \\
\hline Philippines & 34 & 29 & 0.998 & 11 \\
\hline Colombia & 32 & 24 & 0.995 & 12 \\
\hline Peru & 37 & 28 & 0.994 & 13 \\
\hline Brazil & 25 & 23 & 0.986 & 14 \\
\hline Russian Fed. & 30 & 22 & 0.961 & 15 \\
\hline Vietnam & 28 & 33 & 0.959 & 16 \\
\hline Mexico & 27 & 21 & 0.958 & 17 \\
\hline Ukraine & 34 & 27 & 0.957 & 18 \\
\hline Pakistan & 42 & 39 & 0.949 & 19 \\
\hline Spain & 19 & 16 & 0.945 & 20 \\
\hline Bangladesh & 43 & 40 & 0.943 & 21 \\
\hline Sweden & 4 & 3 & 0.936 & 22 \\
\hline Netherlands & 8 & 8 & 0.907 & 23 \\
\hline Canada & 11 & 3 & 0.906 & 24 \\
\hline Austria & 14 & 13 & 0.893 & 25 \\
\hline Turkey & 31 & 31 & 0.889 & 26 \\
\hline Denmark & 2 & 10 & 0.888 & 27 \\
\hline Japan & 7 & 8 & 0.881 & 28 \\
\hline France & 13 & 12 & 0.867 & 29 \\
\hline Taiwan & 8 & 18 & 0.860 & 30 \\
\hline Egypt & 23 & 35 & 0.853 & 31 \\
\hline Korea & 16 & 17 & 0.852 & 32 \\
\hline Switzerland & 3 & 5 & 0.847 & 33 \\
\hline Morocco & 22 & 37 & 0.846 & 34 \\
\hline China & 17 & 30 & 0.842 & 35 \\
\hline Uganda & 39 & 41 & 0.841 & 36 \\
\hline Indonesia & 24 & 34 & 0.835 & 37 \\
\hline Germany & 5 & 15 & 0.830 & 38 \\
\hline Thailand & 18 & 25 & 0.815 & 39 \\
\hline India & 21 & 38 & 0.795 & 40 \\
\hline Ethiopia & 45 & 45 & 0.794 & 41 \\
\hline South Africa & 20 & 36 & 0.761 & 42 \\
\hline Tanzania & 44 & 44 & 0.755 & 43 \\
\hline Kenya & 41 & 42 & 0.723 & 44 \\
\hline Nigeria & 37 & 43 & 0.721 & 45 \\
\hline
\end{tabular}


Table 3 Summary of results

\begin{tabular}{lcc} 
Group & No. of countries & $\begin{array}{c}\text { Average of } \\
\text { DEA score }\end{array}$ \\
\hline Africa & 10 & 0.828 \\
Asia & 10 & 0.879 \\
Australia & 1 & 1.025 \\
Europe & 16 & 0.962 \\
North America & 2 & 0.999 \\
South America & 6 & 1.021 \\
\hline G7 & 7 & 0.974 \\
E7 & 7 & 0.895 \\
OECD & 20 & 0.959 \\
\hline Grand Total & 45 & 0.925 \\
\hline
\end{tabular}

Table 4 Averages of projections of outputs for different country groups

\begin{tabular}{|c|c|c|c|c|c|c|c|c|c|c|}
\hline \multirow[b]{2}{*}{ Group } & \multirow[b]{2}{*}{$\begin{array}{l}\text { No. of } \\
\text { Countries }\end{array}$} & \multicolumn{3}{|c|}{ LIFEXP* } & \multicolumn{3}{|c|}{ ENROLL** } & \multicolumn{3}{|c|}{ GDPCAP $* * *$} \\
\hline & & Actual & Projection & $\begin{array}{r}\% \text { of } \\
\text { Difference }\end{array}$ & Actual & Projection & $\begin{array}{r}\% \text { of } \\
\text { Difference } \\
\end{array}$ & Actual & Projection & $\begin{array}{r}\% \text { of } \\
\text { Difference } \\
\end{array}$ \\
\hline Africa & 10 & 55.33 & 69.16 & $24.99 \%$ & 60.40 & 79.51 & $31.64 \%$ & 3134.5 & 12234.1 & $290.31 \%$ \\
\hline Asia & 10 & 70.86 & 81.05 & $14.39 \%$ & 72.00 & 90.14 & $25.20 \%$ & 9826.0 & 19418.0 & $97.62 \%$ \\
\hline Australia & 1 & 80.30 & 82.19 & $2.35 \%$ & 116.00 & 113.15 & $-2.46 \%$ & 29143.0 & 28427.4 & $-2.46 \%$ \\
\hline $\begin{array}{l}\text { Europe } \\
\text { North }\end{array}$ & 16 & 76.51 & 83.63 & $9.31 \%$ & 95.50 & 101.82 & $6.62 \%$ & 23541.8 & 25731.1 & $9.30 \%$ \\
\hline $\begin{array}{l}\text { America } \\
\text { South }\end{array}$ & 2 & 78.70 & 83.12 & $5.62 \%$ & 93.50 & 98.50 & $5.35 \%$ & 33907.5 & 33919.5 & $0.04 \%$ \\
\hline America & 6 & 72.57 & 72.48 & $-0.13 \%$ & 82.33 & 85.09 & $3.36 \%$ & 7574.8 & 9265.4 & $22.32 \%$ \\
\hline G7 & 7 & 79.44 & 85.13 & $7.16 \%$ & 94.57 & 100.79 & $6.58 \%$ & 29295.6 & 30419.9 & $3.84 \%$ \\
\hline E7 & 7 & 68.76 & 77.82 & $13.18 \%$ & 74.14 & 87.52 & $18.04 \%$ & 6302.1 & 15450.1 & $145.16 \%$ \\
\hline OECD & 20 & 78.23 & 85.42 & $9.19 \%$ & 95.35 & 102.28 & $7.27 \%$ & 25708.3 & 27183.8 & $5.74 \%$ \\
\hline $\begin{array}{l}\text { Grand } \\
\text { Total }\end{array}$ & 45 & 70.20 & 78.30 & $11.54 \%$ & 81.09 & 92.14 & $13.63 \%$ & 14415.1 & 19557.3 & $35.67 \%$ \\
\hline
\end{tabular}

* Life expectancy at birth, ** Combined gross enrolment ratio for primary, secondary, and tertiary schools, *** GDP per capita 
Table 5. Projections for E7 Countries

\begin{tabular}{|c|c|c|c|c|c|c|c|}
\hline Country & DEA Score & BASREQ $^{1}$ & EFFENH $^{2}$ & INSOPF $^{3}$ & LIFEXP $^{4}$ & ENROLL $^{5}$ & GDPCAP $^{6}$ \\
\hline Brazil & 0.986 & $0.00 \%$ & $-12.90 \%$ & $-21.95 \%$ & $4.21 \%$ & $1.38 \%$ & $1.38 \%$ \\
\hline China & 0.841 & $0.00 \%$ & $-2.62 \%$ & $0.00 \%$ & $18.86 \%$ & $30.89 \%$ & $275.18 \%$ \\
\hline India & 0.795 & $0.00 \%$ & $-3.97 \%$ & $-6.31 \%$ & $25.71 \%$ & $44.05 \%$ & $823.76 \%$ \\
\hline Indonesia & 0.835 & $0.00 \%$ & $0.00 \%$ & $-1.66 \%$ & $19.78 \%$ & $28.55 \%$ & $413.72 \%$ \\
\hline Mexico & 0.958 & $0.00 \%$ & $-4.56 \%$ & $-2.25 \%$ & $4.35 \%$ & $8.71 \%$ & $4.35 \%$ \\
\hline \multicolumn{8}{|l|}{ Russian } \\
\hline Federation & 0.938 & $0.00 \%$ & $0.00 \%$ & $-3.83 \%$ & $8.51 \%$ & $6.64 \%$ & $59.40 \%$ \\
\hline Turkey & 0.888 & $0.00 \%$ & $0.00 \%$ & $-2.12 \%$ & $12.59 \%$ & $19.52 \%$ & $95.46 \%$ \\
\hline
\end{tabular}

Table 6 Importance of various criteria in affecting DEA scores

Criteria affecting DEA scores Weight

\begin{tabular}{ll}
\hline GDPCAP $^{1}$ & 0.549 \\
LIFEXP $^{2}$ & 0.246 \\
EFFENH $^{3}$ & 0.101 \\
INSOPF $^{4}$ & 0.057 \\
ENROLL $^{5}$ & 0.035 \\
BASREQ $^{6}$ & 0.012
\end{tabular}

${ }^{1}$ GDP per capita, ${ }^{2}$ Life expectancy at birth, ${ }^{3}$ Efficiency

enhancers, ${ }^{4}$ Innovation and sophistication factors, ${ }^{5}$ Combined

gross enrolment ratio for primary, secondary, and tertiary

school, ${ }^{6}$ Basic requirements 


\section{Acknowledgements}

The authors are grateful to REF - The TUSIAD Sabanci University Competitiveness Forum for their help in gathering the data. 